\title{
Community-based Programs for Childhood Immunization and Prevention of Childhood Diseases: Sustainable Support in Mothers' Decision-Making - A Health Belief Model Approach
}

Jonas Kemeugni Ngandjon ( $\square$ kjonas25@yahoo.fr)

Universitat Witten/Herdecke https://orcid.org/0000-0001-5357-2908

Alfred Laengler

University of Witten/Herdecke: Universitat Witten/Herdecke

Thomas Ostermann

University of Witten/Herdecke: Universitat Witten/Herdecke

\section{Research article}

Keywords: Community-based Programs, Health education programs, Herd immunity, Health-seeking behavior, Vaccination failure, Community-related framework, Vaccination program, Vaccination coverage, Health Belief Model.

Posted Date: October 13th, 2020

DOI: https://doi.org/10.21203/rs.3.rs-89501/v1

License: (c) (1) This work is licensed under a Creative Commons Attribution 4.0 International License.

Read Full License 


\section{Abstract}

Background: The childhood vaccination program (EPI) is claimed by the World Health Organization (WHO) as the most cost-effective intervention to reduce child mortality. Therefore, in low-income countries governments and health authorities invest in vaccination programs to reach the herd immunity. However, despite the resources allocated to the EPI, epidemics preventable through vaccines are still reported in these countries. In Cameroon, the Foumbot district in the West region has witnessed measles epidemics since 2010 and in 2013 a polio outbreak was reported.

Methods: The design of this study is a cross-sectional survey. A total of 160 mothers of children between the ages of 12 to 23 months were interviewed. The Health-Belief-Model was applied to design a community-related framework regarding maternal decision-making.

Results: The outcome of this survey shows that $60 \%$ of the children studied were completely vaccinated, $37.75 \%$ were partially vaccinated, and $1.25 \%$ had not received any vaccine. The logistic regression analysis shows that affiliation to Islam $(\mathrm{OR}=0.2)$ and a poor knowledge of infectious diseases $(\mathrm{OR}=0.3)$ were significant predictors of complete childhood vaccination failure.

Conclusion: Starting the vaccination program at birth and a good knowledge of infectious diseases were important factors for complete childhood vaccination. Additionally, health facilities presented a shortage of qualified health personnel. Public health authorities should invest in health education programs with the goal of developing skills for health- seeking behavior in individuals and communities.

\section{Background}

Prevention of children of diseases is the primary concern of pediatrics [1][3][4]. Since 1974, in order to reach the herd immunity, the WHO (World Health Organization) motivates health authorities all around the world to invest in the EPI (Expanded Program on Immunization) to ensure vaccination around the world of children against childhood vaccine-preventable diseases (VPDs). Six vaccine-preventable diseases are recommended by the EPI: tuberculosis, polio, diphtheria, tetanus, measles, and pertussis [2].

In 2014, the herd immunity threshold in low-income countries was still below the $92-95 \%$ set by the WHO for VPDs except the BCG vaccine Table 1] [10] [22].

\section{Table 1}

Vaccination coverage, by vaccine and World Health Organization (WHO) region* - worldwide, 2014 [22] 


\begin{tabular}{|l|l|l|l|l|l|l|l|l|l|l|l|}
\hline \multirow{2}{*}{ WHO region } & \multicolumn{9}{|l|}{ Vaccination coverage $(96)$} \\
\cline { 2 - 13 } & BCG & HepB & Hep B3 & DPT3 & Hib3 & Polio3 & Rota last & PCV3 & Rubella & MCV1 & MCV2 \\
\hline $\begin{array}{l}\text { Total } \\
\text { (worldwide) }\end{array}$ & 91 & 38 & 82 & 86 & 56 & 86 & 19 & 31 & 46 & 85 & 56 \\
\hline African & 84 & 10 & 77 & 77 & 77 & 77 & 30 & 50 & 10 & 73 & 11 \\
\hline Americas & 95 & 69 & 88 & 90 & 90 & 90 & 71 & 83 & 92 & 92 & 51 \\
\hline $\begin{array}{l}\text { Eastern } \\
\text { Mediterranean }\end{array}$ & 89 & 24 & 83 & 82 & 72 & 82 & 22 & 45 & 42 & 77 & 66 \\
\hline European & 94 & 39 & 82 & 95 & 85 & 95 & 7 & 44 & 94 & 94 & 84 \\
\hline $\begin{array}{l}\text { South-East } \\
\text { Asia }\end{array}$ & 92 & 29 & 75 & 84 & 30 & 83 & 0 & 0 & 12 & 84 & 59 \\
\hline Western Pacific & 97 & 80 & 92 & 96 & 21 & 97 & 1 & 2 & 91 & 97 & 93 \\
\hline
\end{tabular}

* Weighted regional average.

In Cameroon, the proportion of children below 2 years of age who are completely vaccinated for all recommended childhood vaccines [7][27][28] is still well below the $80 \%$ of eligible children targeted by the Cameroonian government [11].

In September 2013, many cases of paralysis were reported in Foumbot district and Malentuen district in Cameroon. The Genotyping of the viruses showed that a similar virus (Wild Poliomyelitis Virus) affected all the children [12]. Interestingly, the affected children in Cameroon had never been outside the country. The virus genotype linked to the outbreak shows a parenthood to the poliovirus observed in Chad in 2011 [23].

The Foumbot district is a place at risk because of the outbreak. The district hosts one of the largest border fresh-food markets in Cameroon where people from all parts of the country and neighboring countries of Cameroon such as Niger, Chad, Central African Republic, Congo, Gabon, Equatorial Guinea, and Nigeria interact. The risk of expansion of the poliovirus to other parts of the country and to the neighboring countries is high. The parents of the first confirmed cases were farmers and gardeners who used to visit markets in Malentuen [12]. Although vaccination programs to eradicate measles around the country had already been implemented, a proliferation of measles was reported in nine health districts including the Foumbot district, [24]. Despite the financial resources allocated to the EPI to achieve the herd immunity, VPDs remain a health care concern in Cameroon. The sole provision of vaccination does not guarantee the herd immunity throughout the country [7][27]. Only the BCG coverage, which is given at birth, is above $90 \%$. The coverage of other vaccines in children is still far below $80 \%$ expected in all health districts. [7][11]. Based on actual experiences gained by vaccination practice in each region or community, it is possible to define the causes of reticence to the vaccination [29] [30][31]. Therefore, programs leading to a higher prevention of infectious diseases in the population can only be defined, once the underlying reasons for the refusal and/or the interruption of the vaccination program are clearly identified. This study identifies, examines the factors affecting the intention to get children below the age of two in Foumbot district completely vaccinated using the Health Belief Model as well as defining programs that are likely to better support mothers' decision-making regarding immunization and prevention of childhood diseases. 


\section{Methods}

Setting

The Foumbot district covers an area of about $1000 \mathrm{~km}^{2}$. The district is rural and located in the Noun Division, West region of Cameroon. In 2013, the health district estimated the population to be 62,776 inhabitants (from the 2013 Census), the majority being Bamum. The predominant religion is Islam. Farming is the main occupation. The district hosts the most important fresh food market in the western region and is divided into eleven health communities, which provide EPI to the local population.

Study design

A cross-sectional survey of mothers of children aged 12 to 23 months was performed from $1 \mathrm{st}$ March to 1st June 2014. This included a questionnaire to record mother and children characteristics, and to evaluate maternal knowledge about vaccination. Only mothers or caretakers of the children were interviewed. Survey participants were selected randomly according to the WHO vaccination coverage cluster survey sampling [5][6]. The vaccination coverage have been evaluated by means of the vaccination booklet and EPI register. A child was said to be complete vaccinated if he had received all of the vaccines recommended by the EPI by the time he was selected for the survey.

\section{Participants}

During the investigation, data from 160 children and 160 mothers or caretakers were collected in the district randomly. The sampling process was performed according to the simple random sample (SRS) method [5][6]. The first household was randomly chosen from each selected cluster. Each household was chosen randomly, such that each household had the same probability in the cluster of being chosen during the sampling process [9]. The sampling technique applied allows the researcher to perform the evaluation with a sample that is representative. From this sample, statistical values have been generated to be extrapolated to the whole population of the Foumbot health district.

Data Analysis

The data from the interview were coded and entered into a computer database using Microsoft Office Excel 2010. Descriptive statistics were performed by means of EPI info 3.5.4 statistical software program to analyze the sample, to check the association of each independent variable with the complete vaccination. For this purpose, the odds ratios were calculated along with $95 \%$ confidence intervals $(\mathrm{Cl})$ and the $p$-value from the Fisher's exact test. The threshold for statistical significance was set at $p$-value < 0.05 to evaluate each of the sociodemographic variables as statistically significant as they relate to complete vaccination [Table 3]. Subsequently, by means of the statistical software program SPSS, logistic regression analysis was performed to identify factors that have influenced maternal decisionmaking regarding complete vaccination in children below the age of two. The definition of the immunization programs to support mothers' decision-making regarding immunization was performed by 

[27].

\section{Findings And Childhood Vaccination Status}

\subsection{Status of Vaccination in the Foumbot District}

The vaccination status of the child was established by the records in the vaccination booklet, the records in the EPI registration or by the presence of scar in the case of BCG. In the 5 clusters, a total of 160 households were surveyed. It was found that $96(60 \%)$ children had received complete vaccination at the age of two. On the other hand $62(38.75 \%)$ had received partial vaccination and $2(1.25 \%)$ had not received any vaccine. The dropout rate between the initial vaccine BCG or OPV 0 and the final vaccine measles is quite high with $36 \%$; that means, over one third of the children were not able to complete the vaccination program [Table 2].

Table 2: Vaccination coverage from Foumbot district for each antigen compared to latest data for Cameroon from WHO and Sociodemographic Health Survey (DHS)

\begin{tabular}{|c|c|c|c|c|c|}
\hline \multirow[b]{2}{*}{ Vaccine } & \multirow[b]{2}{*}{$\begin{array}{l}\text { Case } \\
\text { Present } \\
\text { study } \\
\text { (no160) }\end{array}$} & \multirow{2}{*}{$\begin{array}{l}\text { Percentage } \\
\text { Present } \\
\text { study } \\
(n=160) \\
\%\end{array}$} & \multirow[b]{2}{*}{$\begin{array}{l}\text { WHO } \\
\text { (2013) } \\
\times\end{array}$} & \multicolumn{2}{|c|}{ DHS (2011) } \\
\hline & & & & $\begin{array}{c}\text { Cameroon } \\
\begin{array}{c}(n=2265) \\
\%\end{array}\end{array}$ & $\begin{array}{c}\text { West Region, } \\
\text { Cameroon }(n=272) \\
\%\end{array}$ \\
\hline BCG & 158 & 98.8 & 82 & 87.1 & 95.9 \\
\hline Polio 0 & 158 & 98.8 & n.a & 71.7 & 84.4 \\
\hline DPT 1 & 144 & 90 & 95 & 85.5 & 94,4 \\
\hline DPT 2 & 134 & 83.8 & 89 & 78.3 & 87 \\
\hline DPT 3 & 125 & 78.1 & 89 & 68.4 & 75.5 \\
\hline OPV 1 & 143 & 89.4 & n.a & 93.3 & 92.5 \\
\hline OPV 2 & 134 & 83.8 & n.a & 85.5 & 87.5 \\
\hline OPV 3 & 124 & 77.5 & 88 & 69.8 & 76.6 \\
\hline VAA (Yellow Fever) & 101 & 63.1 & 83 & 69.3 & 77.7 \\
\hline VAR (Measles) & 101 & 63.1 & 83 & 70.6 & 79.8 \\
\hline Not vaccinated & 2 & 1.25 & n.a & 4.5 & 2.3 \\
\hline $\begin{array}{l}\text { Completely } \\
\text { vaccinated }\end{array}$ & 96 & 60 & n.a & 52.1 & 62.9 \\
\hline Partially vaccinated & 62 & 38.75 & n.a & 43.4 & 34.8 \\
\hline
\end{tabular}

Table 3: Sociodemographic characteristics and complete childhood vaccination in Foumbot district, Cameroon 2014 


\begin{tabular}{|c|c|c|c|c|c|c|c|}
\hline \multirow[t]{3}{*}{ Factors } & \multirow{2}{*}{\multicolumn{2}{|c|}{ Categorical variables }} & \multicolumn{2}{|c|}{ Complete Vaccination } & & \multicolumn{2}{|c|}{ Binary logist ic } \\
\hline & & & Yes & No & Total & OR $195 \% C l l$ & P. Value \\
\hline & & & $N=96(36)$ & $N=64(\%)$ & $N=160 \quad(\%)$ & & \\
\hline \multirow{8}{*}{ Edu cation } & \multirow{2}{*}{ Noschool } & Yes & $0<0\}$ & $2(100)$ & $2(1.3)$ & 0 & 0.158 \\
\hline & & Nan & $96\{60.8\}$ & $62(39.2)$ & $158(98.8)$ & & \\
\hline & \multirow{2}{*}{ Primary } & Yes & $37(54,4)$ & $31(45.6)$ & $68(42.5)$ & $0.67(0.35-1.26\}$ & 0.141 \\
\hline & & $\mathrm{Nan}$ & 59164.11 & 33135,91 & 92157.51 & & \\
\hline & \multirow{2}{*}{ Secondary } & Yes & $57(64.8)$ & $31(35.2\}$ & $88(55)$ & $1.55\{0.82-2.94\}$ & 0.115 \\
\hline & & Nan & $39(54.2)$ & $33(45.8)$ & $72(45)$ & & \\
\hline & \multirow{2}{*}{ University } & Yes & $2(100)$ & 0 & $2\{1.3\}$ & & 0.36 \\
\hline & & Nan & $94(59.5)$ & $64(40.5)$ & $15(98.8)$ & & \\
\hline \multirow{8}{*}{$\begin{array}{l}\text { Child Birth } \\
\text { order }\end{array}$} & \multirow{2}{*}{ 1st } & Yes & $27(67.5)$ & $13(32.5)$ & $40\{25\}$ & $1.53(0.72-3.26\}$ & 0.176 \\
\hline & & Nan & $69(57.5)$ & $51(42.5)$ & $120(75)$ & & \\
\hline & \multirow{2}{*}{ 2nd } & Yes & $32(68.1)$ & $15(31.9)$ & $47\{29.4\}$ & $1.63(0.79-3.34)$ & 0.121 \\
\hline & & Nan & $64(56.6)$ & $49(43.4)$ & $113\{70.6\}$ & & \\
\hline & \multirow{2}{*}{$3 \mathrm{rd}$} & Yes & $14(50)$ & $14(50)$ & $28\{17.5\}$ & $0.61(0.26-1.38)$ & 0.164 \\
\hline & & Nan & $82(62.1)$ & $50(37.9)$ & $132(82.5)$ & & \\
\hline & \multirow{2}{*}{$>3$} & Yes & $23(51.1)$ & $22(48.9)$ & $45\{28.1\}$ & $0.6(0.29-1.20\}$ & 0.105 \\
\hline & & Nan & $73(63.5)$ & $42(36.5)$ & 115 (71.9) & & \\
\hline \multirow{7}{*}{ M arital St atus } & sincle & Yes & $17\{81\}$ & $4(19)$ & $21(13.1)$ & $3.23(1.03-10.09)$ & 0.028 \\
\hline & Sing ice & Nan & $79(56.8)$ & $60(43.2\}$ & 139 (86.9) & & \\
\hline & Married & Yas & 7945721 & 59.42 .81 & $128 / 86.31$ & $0.393(0.13-1.12$ & 0.06 \\
\hline & Married & $\mathrm{Nan}$ & 1717231 & 512271 & 22013.81 & & \\
\hline & Widow & Yes & 0 & $1(100)$ & $1(0.61$ & 0 & 0.4 \\
\hline & & Nan & $96(60.4)$ & $63\{39.6\}$ & $159\{99.4\}$ & & \\
\hline & Divorced & Nan & $96(60)$ & $64(40)$ & $160(100)$ & & \\
\hline & & Yes & $12(75)$ & $4(25)$ & $16\{10\}$ & $2.14\{0.65-6.96\}$ & 0.1533 \\
\hline & Casthonic & Nan & $84\{58.3\}$ & $60(41.7)$ & $144(90)$ & & \\
\hline & Protestant & Yes & 24182.81 & 5117.21 & $29\lfloor 18.1\rfloor$ & $3.93(1.41-10.94$ & 0.004 \\
\hline Religion & Proverant & Nan & $72(55)$ & $59(45)$ & 131 (81.9) & & \\
\hline & Muslim & Yes & $60(52.2)$ & $55(47.8)$ & $115(71.9)$ & $0.27 \mid 0.12-0.61\}$ & 0.001 \\
\hline & 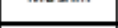 & $\mathrm{Nan}$ & 361801 & $9(20)$ & $45 / 28.1)$ & & \\
\hline & Animist & $\mathrm{Nan}$ & 964601 & 64,401 & 1604001 & & \\
\hline & Formal & Yes & $8(66.7)$ & $4(33.31$ & $12\lfloor 7.5\}$ & $1.36 \mid 0.39-4.731$ & 0.434 \\
\hline Orcupations & sector & Nan & $88(59.5)$ & $60(40.5)$ & $148(92.5)$ & & \\
\hline 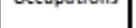 & Informal & Yes & $88(59.5)$ & $60(40.5)$ & $148(92.5)$ & $0.73(0.21-2.54\}$ & 0.434 \\
\hline & Sector & Nan & 8166.71 & $4,33.3\}$ & $12\{7.5$ & & \\
\hline & Prevent the & Yes & $64(58.7)$ & $45(41.3)$ & $109\{68.1\}$ & $0.84\{0.42-1.67\}$ & 0.379 \\
\hline & $\begin{array}{l}\text { afdiveaves } \\
\text { nat }\end{array}$ & Nan & $32(62.7)$ & $19(37.3)$ & $51(31.9)$ & & \\
\hline Reason for & De crease & Yes & $1(50)$ & $1(50)$ & $2\{1.2\}$ & $0.66(0.04-10.79)$ & 0.641 \\
\hline vacc inst ing & $\begin{array}{l}\text { the severity } \\
\text { of diseases }\end{array}$ & Nan & $95(60.1)$ & $63(39.9)$ & $158(98.8)$ & & \\
\hline & No ides & Yes & $31(163.3)$ & $18(36.7)$ & $49(30.6)$ & $1.2(0.61-2.4\}$ & 0.35 \\
\hline & & Non & 65 (58.6) & $46(41.4)$ & 111 (69.4) & & \\
\hline & Good & Yes & $8(100)$ & 0 & $8(5)$ & - & 0.015 \\
\hline & kn owledge & Nan & $88(57.9)$ & $64(42.1)$ & $152(95)$ & & \\
\hline & Average & Yes & $14(6.6 .7)$ & $7\{29.2\}$ & $21(13)$ & $1.4(0.52-3.66\}$ & 0.34 \\
\hline VDP and & kn owledge & Nan & $82(59)$ & $57\{41\}$ & $139(87)$ & & \\
\hline in fectious & Insufficient & Yes & $66(60.6)$ & $43(39.4)$ & 109 \{68.1\} & $1.07\{0.54-2.11\}$ & 0.484 \\
\hline & kn owledge & Nan & $30(58.8)$ & $21(41.2)$ & $51(31.9)$ & & \\
\hline & Poor & Yes & $8(36.4)$ & $14(63.6)$ & $22(13.8)$ & $0.32\{0.12-0.82\}$ & 0.014 \\
\hline & kn owledge & Nan & $88(63.8)$ & $50(36.2)$ & 138 (86.3) & & \\
\hline & As Pirth & Yes & $83(64.3)$ & $46\{35.7\}$ & $129\{80.6\}$ & $2.5(1.12-5.55)$ & 0.02 \\
\hline & At Eirtin & Nan & $13(41.9)$ & $18\{58.1\}$ & $31\{19.4\}$ & & \\
\hline appro priate & No idea & Yes & $11 / 44 \mid$ & $14 / 561$ & $25\lfloor 15.6)$ & $0.410 .19-1.09$ & 0.06 \\
\hline vacc inst ion & & $\mathrm{Nan}$ & 851634 & 504371 & $135 / 84,31$ & & \\
\hline & Otherdste & Yes & 2633.31 & 446661 & $6 / 3,71$ & $0.3260 .06-1.791$ & 0.17 \\
\hline & & $\mathrm{Nan}$ & 946601 & 604401 & 1541969 & & \\
\hline Mastering of & & Yes & $29(80.6)$ & $7\{19.4\}$ & $36(22.5)$ & $3.52(1.43-8.65)$ & 0.002 \\
\hline \begin{tabular}{|c|}
$\begin{array}{c}\text { vaccination } \\
\text { schedule }\end{array}$ \\
\end{tabular} & Master & Nan & $67(54)$ & $57(46)$ & $124(77.5)$ & & \\
\hline Rete ntion of & Kene & Yes & $88\{62\}$ & $54(38)$ & $142(88.8)$ & $2.04\{0.76-5.48\}$ & 0.121 \\
\hline n hooklet & nets & Nan & $8(44.4)$ & $10(55.6)$ & $18\{11.3\}$ & & \\
\hline
\end{tabular}

\subsection{Sociodemographic Factors and Childhood Vaccination Status}

Besides vaccination coverage, other factors associated with complete childhood vaccination were assessed in this study. The analysis of the association between child vaccination status and sociodemographic factors is essential as protection against infectious diseases and prevention of diseases are communicated through local customs. All the independent variables identified as 
statistically significant were put together in the regression model for analysis. Finally, the model (step 3) shows the smallest value of the AIC, the BIC, and the -2 Log Likelihood statistics [Table 4]. This final model (step 3) is better suited to explain the decision of mothers about childhood vaccination status. The fit of the logistic regression model was successfully validated by generating a Receiver Operating Characteristic (ROC) curve.

Table 4: Step Summary - Information criteria

\begin{tabular}{|c|c|c|c|c|c|c|c|c|}
\hline \multirow[b]{2}{*}{ Model } & \multirow[b]{2}{*}{ Action } & \multirow[b]{2}{*}{ Effect(s) } & \multicolumn{3}{|c|}{ Model Fitting Criteria } & \multicolumn{3}{|c|}{ Effect Selection Tests } \\
\hline & & & AIC & BIC & $\begin{array}{c}-2 \text { Log- } \\
\text { Likelihood }\end{array}$ & Chi-square & $\begin{array}{l}\text { degree of } \\
\text { freedom }\end{array}$ & Significance \\
\hline 0 & Entered & Constant & 85.70 & 88.78 & 83.70 & . & & \\
\hline 1 & Entered & Muslim & 76.58 & 82.73 & 72.58 & 11,12 & 1 & 0.001 \\
\hline 2 & Entered & Start at birth & 67.74 & 76.97 & 61.74 & 10.84 & 1 & 0.001 \\
\hline 3 & Entered & $\begin{array}{c}\text { Poor } \\
\text { Knowledge } \\
\text { of VPDs }\end{array}$ & 64.16 & 76.46 & 56.14 & 5.58 & 1 & 0.018 \\
\hline
\end{tabular}

Stepwise Method: Forward Selection

a. The Chi-Square for entry is based on the Likelihood-Ratio-Test

\section{a. Factors Promoting Childhood Vaccination}

It was observed that mothers who attended secondary school and university were 1.6 times more likely to have their children completely vaccinated than women who attended only primary school. Mothers without school background did not even know about vaccination. In the bivariate analysis, this survey identified the association between mastering the vaccination schedule and childhood vaccination status as statistically significant [Table 3]. Children whose mothers mastered the vaccination schedule were 3.5 times [OR $=3.5]$ more likely to receive complete vaccination than children whose mothers did not know about it. $41.3 \%$ of the mothers knew about the vaccination schedule and $22.5 \%$ mastered it. Consequently, $77.5 \%$ of mothers do not know about the schedule of the vaccination program and the number of vaccines to be taken. In the regression analysis [Table 3], the age-appropriate vaccination was statistically significant and associated to the vaccination status. The results show that this factor was beneficial to increase complete vaccination status in children. Children whose mothers start vaccination at birth were 4.8 times [OR $=4.8]$ more likely to receive complete vaccination. About the marital status, single mother were 3.2 times more likely to complete the vaccination program than mothers who were married [Table 3].

\section{b. Factors hindering Childhood Vaccination}

A high amount of partial vaccination were reported among Muslim mothers [Table 3]. In the Muslim group, $47.8 \%$ of the mothers failed complete child vaccination program while $20 \%$ were reported in other religious groups. In this study $68 \%$ of mothers show insufficient knowledge of infectious diseases and VPDs. In the group of mothers with insufficient knowledge of VPDs and infectious diseases, only $36.4 \%$ 
succeeded complete child vaccination program. In the final logistic regression model, it was identified that the religious affiliation to Islam and poor knowledge of VPDs were relevant predictors of complete childhood vaccination failure in the Foumbot district [Table 4].

\section{Discussion}

\subsection{Maternal Perceptions on the Vaccination}

My experiences, my belief

The outcome of this study reveals that mothers' decisions were made according to their perceptions of the vaccination practice. These perceptions were built out of the local value system [Figure 1]. The factors that have been identified in this study show the existence of three types of status of vaccination in the study area: complete vaccination, partial-vaccination, and non-vaccination [Figure 1]. These status express evidence that different perceptions with regard to childhood vaccination are present in the study area: social demand, acceptance, and refusal. In 1995, when Mark Nichter questioned the EPI, he identified the perceptions "acceptance" and "refusal" [33]. The perception "acceptance" was differentiated into two categories: "active acceptance" and "passive acceptance". In "active acceptance", people would participate in the vaccination program as expected by the EPI, and in "passive acceptance", people would accept vaccination during a campaign, but the need would not be maintained beyond the end of the vaccination program [33]. The perception "refusal" was defined as the complete refusal of vaccination.

Subsequently, in 1999, Nichter's model was expanded by Streefland to determine possible perceptions on the vaccination. Streefland identified the perception "social demand". This perception is active and associated with a perception of some general or particular advantage associated with vaccination [30] [32].

This study shows that $5 \%$ of the mothers had a good knowledge of VPDs [Figure 1]. All these mothers with a good knowledge of VPDs had completed the vaccination program. A good knowledge of VPDs and infectious diseases is expected to generate and maintain the perception "social demand" even though the conditions in a community are not in favor of the vaccination. The factor "start at birth" is beneficial to the complete vaccination. This factor establishes a contact between mothers and the medical system. Although $98 \%$ of children had received BCG "at birth", only $63.1 \%$ of children had received measles vaccines at the age of two. This shows that the confidence in the biomedical system is not established. Consequently, some mothers' perceptions shifted from active-acceptance to passive-acceptance.

When mothers do not have confidence in the medical system, they get information regarding health in their local value system. This study shows that the factor "poor knowledge of VPDs" predicts the following vaccination status: partial vaccination (passive acceptance) and none vaccination (refusal). These vaccination status express the absence of knowledge regarding evidence-based medicine (EBM) and in turn about the immunization. It follows then a misinterpretation of VPDs and side effects associated with vaccination. Therefore, vaccination is interrupted or refused because it is perceived as a 
danger for the children. Affiliation to Islam was also found as a predictor of the vaccination failure in children, even though mothers' perception regarding vaccination was not generated according to the religious principles but according to people's perceptions in the community. African communities and particularly Muslim communities are regularly impacted by negative information [19][21] regarding vaccination programs. The perception of mothers living in these communities regarding vaccination is likely to turn into refusal following rumors often linked to a conspiracy theory [34][35]. Because of the slave trade and the colonization, many Africans and particularly Muslims are skeptical and suspicious about any intervention from western countries [20] and those who refuse vaccination perceive the EPI as a western propaganda to destroy Africans, Muslims and their local traditions and cultures [13][14][15][16] [17][18], [28]. Most people on the African continent and particularly in rural area like the Foumbot district cannot identify with the vaccination and as result, these people find their identity in the confidence they have in the African local medicine.

\subsection{Maternal Decision-Making}

I do what I know, and what I know results from what I was taught.

Maternal decision for vaccinating was influenced by the understanding of prevention, protection and healing, the interpretation of disease and illness and its consequences, the way mothers perceived the consequences of their vaccination decision and their child's predisposition to disease, and the consequences that vaccination will probably have on the child.

This outcome shows that a good knowledge of VPDs and mechanism of infectious diseases may not be a result of the school program only, but also a result of developing skills, especially through sustainable health education programs, which are expected to support mothers to become open-minded and attentive to health information.

\subsection{Cues to Action: Sustainable Support in Mothers' Decision-Making}

"It is often not just what is offered that makes bait out, but how it is perceived by the recipient matters" Simmi Oberoi et al. 2016

Based on the outcomes of this study and the developed community-related framework [Figure 2], immunization and prevention of childhood diseases require a sustainable health education. Supporting mothers' decision-making sustainably through health education demands actions, which focus on the development and the implementation of community-based programs for the promotion of health explanation, health consciousness, and health empowerment.

In this study, the following health education programs have been defined:

- Program 1: Comprehensive clarification at the community level of the mechanism of the disease and monitoring health issues 
- Program 2: Provide information, missing information, and misinformation about immunization and health programs

- Program 3: Development of the "relationship health professionals-mothers"

- Program 4: Acknowledgement of the Local Value System to adapt medical intervention to local needs

- Program 5: Empowerment of individuals and community regarding health issues

- Program 6: Building confidence through local screening of health initiatives

- Program 7: Acknowledgment of alternatives to the vaccination and exploration of their benefits, their limits and their risks.

\section{Limitations Of The Study}

In this study, some limitations were expected because this is a cross-sectional study and the sampling method is susceptible to selection bias. Only the participants that were present in the district at the time of the interview and that met the survey inclusion criteria were considered in the sample.

\section{Conclusions}

This study identified what actions are expected to better support maternal decision-making for the childhood immunization and the prevention of childhood diseases.

The factors "poor knowledge of VPDs and infectious diseases" and "affiliation to Islam" were found to be statistically significant and associated with the failure in childhood vaccinationTable 3]. Islam itself is not against the vaccination. However, it was found that negative information about vaccination is frequently spread around in Muslim communities. The shortage of health personnel in the Foumbot district and in Cameroon in general also limits the populations' access to health information and the trust in the medical system. When mothers have poor knowledge of VPDs and infectious diseases, they are expected not to trust in the vaccination and in turn to refuse or interrupt the EPI.

On the other hand, the factors "good knowledge of VPDs and infectious diseases", and starting vaccination "at birth" were found to be statistically significant and positively associated with complete childhood vaccination [Table 3]. These two factors were advantageous to generate in mothers the perceptions "demand" or "acceptance" of the childhood vaccination.

Based on the data collected from the respondents [Table 3], the vaccination status of the children expresses the perception of mothers in the Foumbot district towards EPI [Figure 1].

In the literature "Patterns of vaccination acceptance", Streefland et al [32] declared that the perceptions demand, acceptance and refusal may or may not be based on a knowledgeable comprehension of the vaccination, but are based on the experience people or community have with it. Following this declaration, this study has found that perceptions of mothers regarding vaccination may or may not be 
based directly on sociodemographic factors, but are based on the interpretation by the local value system of the existing information available in the community [Figure 1].

The findings of this study suggest investing in health education programs targeted at mothers who are poorly educated on infectious diseases. These programs should not be limited to how to avoid illness or how to cope with diseases. It should also focus on the understanding of peoples' local health beliefs and practices, and consider these beliefs and practices in developing health education programs with the purpose of developing skills in health-seeking behavior in individuals and communities [Figure 2]. The understanding of the dynamics of communities regarding health issues will allow tailoring immunization programs to the local context.

\section{Abbreviations}




\begin{tabular}{ll}
\hline AIC & Akaike's Information Criterion \\
\hline AIDS & Acquired Immune Deficiency Syndrome \\
\hline AUC & Area Under the Curve \\
\hline BCG & Bacillus Calmatte Guiren \\
\hline BIC & Bayesian Information Criterion \\
\hline Cl & Confidence Interval \\
\hline CIA & Central Intelligence Agency \\
\hline CMYP & Comprehensive Multiyear Plan \\
\hline df & Degree of freedom \\
\hline DPT & Diphtheria, Pertussis, Tetanus \\
\hline EBM & Evidence Based Medicine \\
\hline ECDC & European Centre for Disease Prevention and Control \\
\hline e.g. & exempli gratia (for example) \\
\hline EPI & Expanded Program on Immunization \\
\hline EXP & Exponential \\
\hline GPEI & Global Polio Eradication Initiative \\
\hline GVAP & Global Vaccine Action Plan \\
\hline HBM & Health-Belief-Model \\
\hline Hib & Haemophilus influenza type b \\
\hline HIV & Human Immunodeficiency Virus \\
\hline i.e. & That is \\
\hline MCV & Measles-Containing vaccine \\
\hline MDO & Millennium Development Objectives \\
\hline MMR & Measles, Mumps and Rubella vaccine \\
\hline NGO & Non-government Organization \\
\hline NID & National Immunization Day \\
\hline Oral Polio Vaccine \\
\hline Odds Ratio \\
\hline Pneumococcal Conjugate Vaccine \\
\hline OPV
\end{tabular}




\begin{tabular}{ll} 
Polio & Poliomyelitis \\
\hline REF & Reference \\
\hline ROC & Receiver Operating Characteristic \\
\hline S.E. & Standard Error \\
\hline Sig. & Significance \\
\hline SRS & Simple random sample \\
\hline TT & Tetanus Toxoid \\
\hline UN & United Nations \\
\hline UNICEF & United Nations Children's Fund \\
\hline USA & United States of America \\
\hline VAA & Vaccin Anti Amaril (yellow fever vaccine) \\
\hline VAR & Vaccin Anti Rougeoleux (measles vaccine) \\
\hline WHA & World Health Assembly \\
\hline VPD & vaccine preventable disease \\
\hline WHO & World Health Organization \\
\hline WPV & Wild Poliomyelitis Virus
\end{tabular}

\section{Declarations}

\section{- Ethics approval and consent to participate}

The ethical approval Autorisation $N^{\circ} 2014 / 036 / U d M / P R / C A B / C I E$ was obtained on the 30th June 2014 from the Institutional Ethic Committee of the Université des Montagnes . Before data collection, written consent was obtained from the respondents.

\section{- Consent for publication}

Not applicable

\section{- Availability of data and materials}

The datasets used and/or analyzed during the current study are available from the corresponding author on reasonable request.

\section{- Competing interests}

The authors declare that they have no competing interests. 
- Funding

Not applicable

\section{- Authors' contributions}

JK was involved in the conception, design, analysis and interpretation of data, and report writing.

AL has been involved in the conception, design, analysis of the data and critically reviewed the manuscript.

TO has assisted with the conception and designing the study and critically reviewed the manuscript

All authors read and approved the final manuscript

\section{- Acknowledgements}

Not applicable

\section{References}

1. Riedel S, (2005), Edward Jenner and the history of smallpox and vaccination..

2. WHO Western Pacific Region. 2017. WPRO / Expanded program on immunization (EPI). [ONLINE] Available at: http://www.wpro.who.int/immunization/en/. [Accessed 26 October 2017].

3. World Health Organization. 2017. WHO / Measles vaccination has saved an estimated 17.1 million lives since 2000. [ONLINE] Available at: http://www.who.int/mediacentre/news/releases/2015/measles-vaccination/en/. [Accessed 26 October 2017].

4. World Health Organization, UNICEF. Global Vaccination Vision and Strategy 2006-2015. Geneva: World Health Organization; 2005.

5. World Health Organization. (2005), Vaccination coverage cluster survey reference manual WHO/IVB/04.23.

6. World Health Organization. (2008), The EPI coverage survey - WHO/IVB/08.07.

7. Institut National de la Statistique Cameroun. (2011), Document de méthodologie de l'enquête sur les connaissances, attitudes et pratiques des populations en matière de vaccination au Cameroun en 2011: CAP 2011.

8. SCHWARTZ D. (1969), Méthodes statistiques à l'usage des médecins et biologistes.

9. United, Nations. (2005), Designing Household Survey Samples: Practical Guidelines.

10. Bennett S, Woods T, Liyanage W, Smith D. (1991), A simplified general method for cluster sample surveys of health in developing countries \&\#8211. 
11. Cameroon Ministry of public Health. (2011), Cameroun-Comprehensive multi-year plan for 20112015.

12. DREF operation $\mathrm{N}^{\circ}$. MDRCM30; November, 2013.

13. Kapp C. (2003), Surge in polio spreads alarm in northern Nigeria. Rumours about vaccine safety in Muslim-run states threaten WHO's eradication program. Lancet.

14. Ambe O. (2001), Perceptions, beliefs and practices of mothers in sub-urban and rural areas towards measles and measles vaccination in Northern Nigeria.

15. Olumuyiwa O, Odusanya EF, Alufohai FP, Meurice, Vincent I, Ahonkhai. (2008), The determinants of vaccination coverage in rural Nigeria. BMC Public Health.

16. Ndèye Magatte NP, Ndiaye A, Diedhiou AS, Gueye. Anta TalDia. Cahiers Santé, (2009), Facteurs d'abandon de la vaccination des enfants âgés de 10 à 23 mois à Ndoulo au Sénégal en 2005.

17. Belachew Etana. (2011), Factors Affecting Immunization Status of Children Aged 12-23 Months in Ambo Woreda, West Shewa Zone of Oromia Regional State Ethiopia 2011. Thèse master en santé publique, School Of Public Health. Addis Abeba University.

18. Abdulraheem I, Onajole A, Jimoh A, Oladipo A. (2011), Reasons for incomplete vaccination and factors for missed opportunities among rural Nigerian children. Journal of Public Health and Epidemiology.

19. IRIN. (2013), NIGERIA: Muslim suspicion of polio vaccine lingers on.

20. Associated Press, (2015), Muslim Clerics Finally Embrace Polio Campaign - Retrieved.

21. HaiderJ. Warraich. (2009), Religious Opposition to Polio Vaccination.

22. Centers for Disease Control and Prevention. (2013), Global Routine Vaccination Coverage, 2014, MMWR (Morbidity and Mortality Weekly Report).

23. Prof. Robinson MBU. Ministry of public health Cameroon, (2014), Independent Monitoring Board (IMB) Global Polio Eradication Initiative (GPEI) Eleventh meeting London.

24. Cameroon WHO office, (2013), Annual Report 2012, 2013.

25. Sturm LA, Mays RM, Zimet GD. Parental beliefs and decision-making about child and adolescent immunization. Pediatr. 2005;26:441-52.

26. Sharon Teitler-Regev. (2011), Factors Affecting Intention among Students to Be vaccinated against A/H1N1 Influenza: A Health Belief Model Approach.

27. Minsante Cameroun. (2015), Cameroun, Enquete par grappes à indicateurs multiples (MICS5) 2014, Rapport de résultats clés.

28. Institut National de la statistique (INS). (Cameroun), 2005, Enquête Démographique et de Santé et à indicateurs multiples, Cameroun.

29. Balinska M, Leon C. (2007), Opinions et réticences face à la vaccination.

30. Streefland PH, Chowdhury AM, Ramos-Jimenez P. (1999), Quality of vaccination services and social demand for vaccination in Africa and Asia.

31. Gellin BG, Schaffner W:, (2002), The risk of vaccination - the importance of "negative" studies. 
32. Streefland P, Chowdhury AMR, Ramos-Jimenez P. (1999), Patterns of vaccination acceptance.

33. Nichter M. (1998) Special issue on the Debate on Selective or Comprehensive Primary Health Care.

34. Stilwell S. (2002), The Imposition of Colonial Rule, Vol. 3, in Colonial Africa.

35. Langwick SA. (2011), Bodies, Politics, and African Healing: The Matter of Maladies in Tanzania.

\section{Figures}

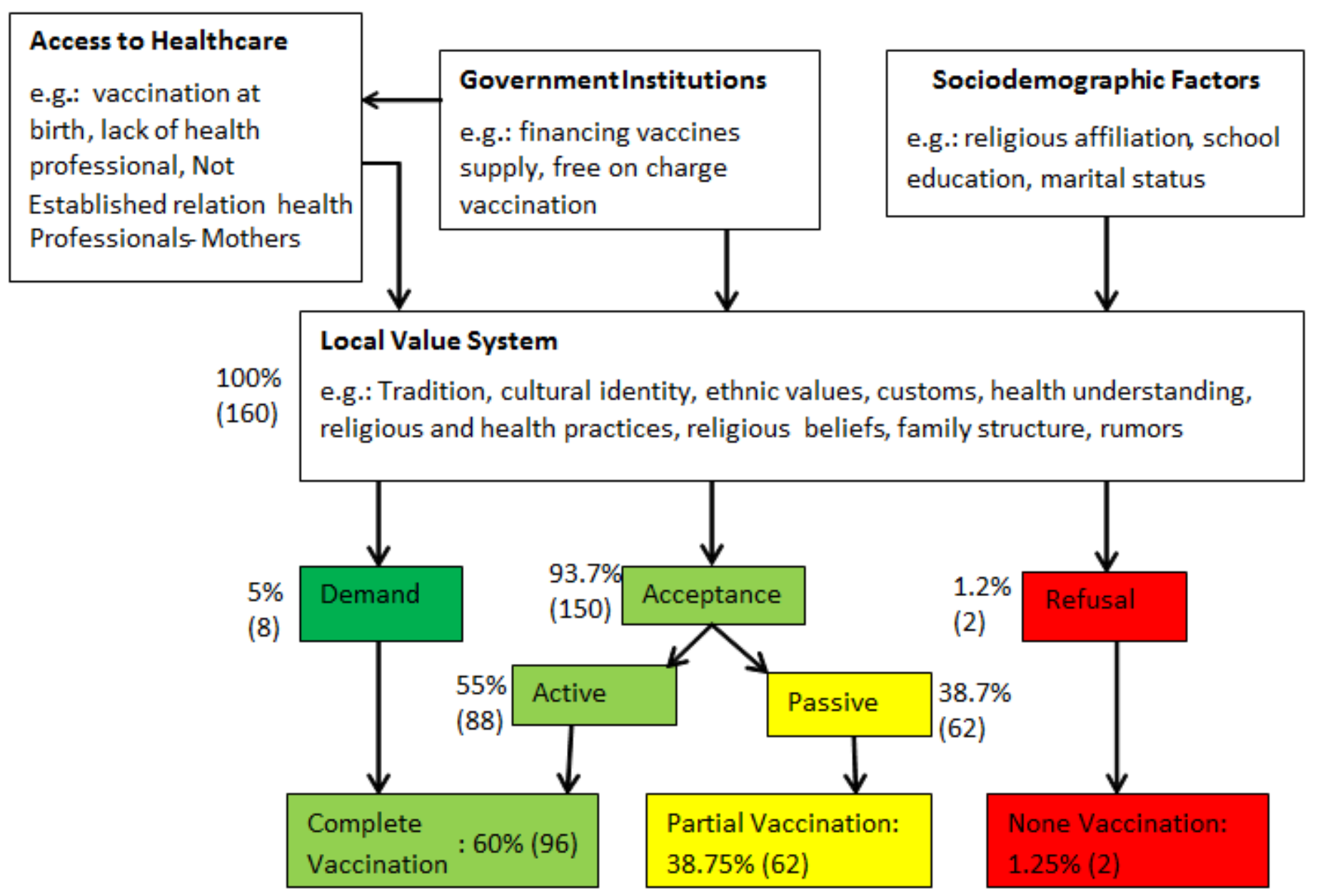

Figure 1

Outcomes of the Local value System 


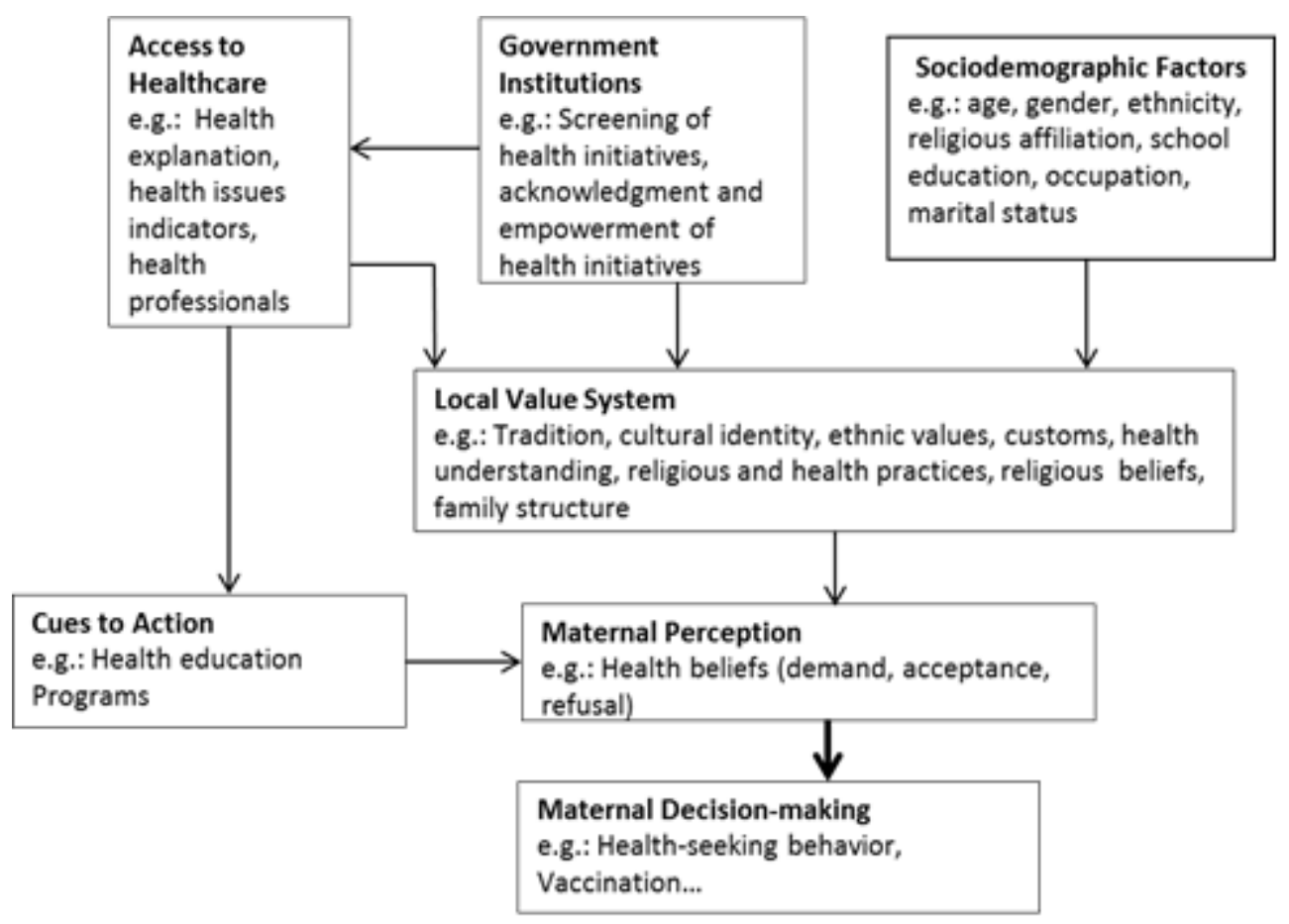

Figure 2

Community-related conceptual framework of maternal decision-making

\section{Supplementary Files}

This is a list of supplementary files associated with this preprint. Click to download.

- STROBEchecklistcrosssectional.doc 